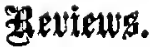

Reference Handbook of the Medical Sciences. Vol. VIII. New York: Wm. Wood \& Co.

This concluding volume of a valuable work comes as carefully prepared and as elaborately illustrated as any of the others. The volume is mostly an appendix and index. In the appendix is embodied much of interest to the neurological as well as to the general student.

We would draw especial attention to the article on the Gross Anatomy of the Brain, by Prof. Burt G. Wilder, of Cornell University. It is certainly a very complete article and of value to the neurological student. The author's original nomenclature, however, interferes with the utility of the article as a ready reference, and we would "consider it somewhat out of place in a "reference handbook" until the time when the terminology used is more universally understood and adopted.

In this same appendix, in an aphoristic article on Terminology, added by Simon H. Gage, Dr. Wilder has given a careful digest o

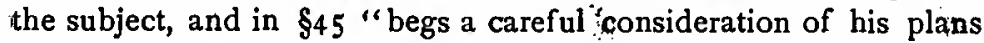
for terminological improvement, because they are based upon unbiased study of nearly all previous publications; . . . because the actual disturbance of existing order of things is kept at a minimum; and because the practical availability of the terms has been demonstrated with hundreds of students in both university and medical school."

Prof. Wilder deserves the support of the profession, undoubtedly, for his wonderful work in a much-needed field. That the work of the student of anatomy will be much aided if the existing terminology were simplified, is without a doubt; and much more so, as Dr. Wilder says finally in a list of reasons, why terms were best if they "remained constant, rather than varied."

We would commend highly also the companion articlesMethods of preparing the Brain, and Brain Malformations-which are morphologically instructive. 
William Browning has contributed a good and well-illustrated article on the Vessels of the Brain.

Leopold Putzel presents an admirable monograph on Acute and Chronic Myelitis.

Frederick Peterson, an article on Cephalocele.

There are two valuable, concise, yet fully descriptive articles, by Dr. E. C. Spitzlia, on the Histology of the Brain, and Anatomy of the Spinal Cord.

The editor, Dr. Albert H. Buck, has finished a creditable work: especially is this observed in his selection of the brightest and bestknown writers from the neurological fields of medicine at home, without foreign aid. The result is that the neurological part of this work is up to date, readable, and crowded with information of practical value.-C. $H$. B.

\section{Which is the Most Powerful} and the Most Reliable of All Pepsins

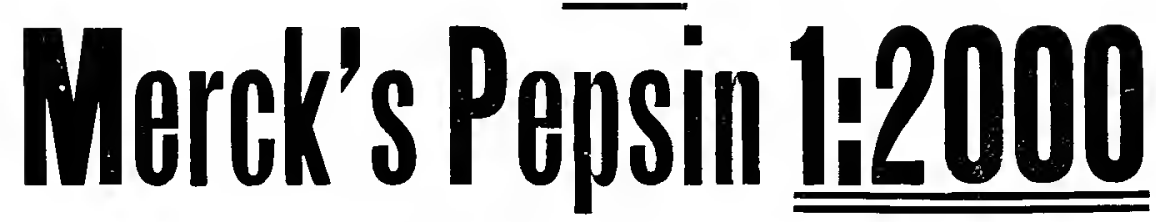

SCALE OR POWDER 